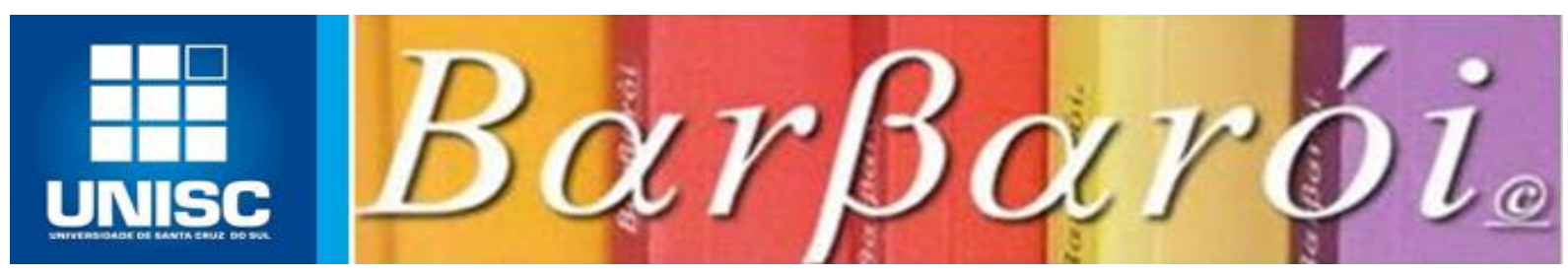

\title{
E QUANDO NÃO É A MÃE? A PATERNIDADE DIANTE DA \\ MONOPARENTALIDADE
}

\author{
DOI: http://dx.doi.org/10.17058/barbaroi.v0i49.5305
}

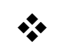 \\ Aline Tomazetti Denardi \\ Centro Universitário Franciscano - UNIFRA - Brasil \\ Cristiane Bottoli \\ Centro Universitário Franciscano - UNIFRA - Brasil
}

\section{Resumo:}

A pesquisa buscou compreender como se caracteriza a monoparentalidade masculina, a partir da separação conjugal, na visão do pai. Atualmente, alguns homens mostram-se cada vez mais interessados em exercer os cuidados e estar próximo dos filhos, mesmo após a separação conjugal e vão em busca de direitos iguais, para ter a guarda dos filhos e poder criá-los pessoalmente. A coleta de dados se deu através de entrevistas individuais, semiestruturadas com três pais, que moram com os filhos. Os resultados mostraram que a constituição da família monoparental masculina se deu de forma distinta para os entrevistados. Quanto às dificuldades encontradas pelos pais neste contexto, eles acreditam que estão relacionadas à fase em que os filhos se encontram e salientam que muitas mães e pais morando na mesma casa também podem enfrentar as mesmas dificuldades relacionadas aos cuidados de um filho. Por isso, é possível que um pai exerça sozinho os cuidados de um filho. Quanto aos desafios, os pais acreditam que seja estar próximos dos filhos, dando-lhes a atenção necessária e ficando mais tempo juntos. Além disso, a percepção que os pais têm sobre o significado de ser pai é que não é uma tarefa fácil, pois exige muitas responsabilidades, grandes desafios e, principalmente, ser participativo no desenvolvimento e na formação dos filhos. Conclui-se, assim, que os pais atualmente estão assumindo uma postura ativa na relação com os filhos, buscando dar conta da paternidade no contexto da monoparentalidade e, com isso, há uma ressignificação da figura paterna para um "novo pai”.

Palavras-chave: Família; Monoparentalidade masculina; Paternidade.

\section{Introdução:}

A família vem passando por importantes modificações ao longo do tempo e estas são decorrentes de mudanças no contexto sociocultural dos indivíduos. De acordo com os apontamentos de Santana (2014), é notório pensar que as famílias não são mais as mesmas, visto que a sociedade é dinâmica e está em constante transformação, assim também é a família, que não é estática e sofre os impactos das mudanças da sociedade. Anteriormente, era possível definir mais facilmente o que é uma família, bem como quais seriam as pessoas 
que compunham esse grupo, sendo que a concepção clássica de família admitia apenas uma configuração do grupo familiar: o homem, a mulher e os filhos. Atualmente, encontra-se maior complexidade ao se tentar definir o que é uma família, pois se observa uma diversidade de configurações familiares na sociedade que, muitas vezes, são consequência de separações, divórcios, casais sem filhos, recasamentos, entre outros.

Ao refletir sobre esse contexto, também é fundamental se pensar a realidade da separação conjugal, que é considerada um acontecimento cada vez mais presente no cotidiano das famílias brasileiras. Diante desta realidade, o grupo familiar como um todo acaba sofrendo mudanças, principalmente quando um dos cônjuges sai de casa, fazendo surgir sentimentos de perda, fracasso, desamparo, abandono, rejeição, medo, insegurança e incertezas, pois, a separação conjugal legaliza um momento de desunião entre o casal, gerando, muitas vezes, um clima de disputa, criando novas estruturas de convivência entre todos os envolvidos.

Diante desta realidade e com as mudanças ocorridas nos paradigmas familiares, ganha destaque a monoparentalidade, que é caracterizada por um dos genitores, o pai ou a mãe, assumir sozinho as responsabilidades pelos filhos. Os casos de monoparentalidade têm aumentado significativamente nas últimas décadas, por isso a importância de se refletir sobre esta realidade. Além disso, grande parte das famílias monoparentais é constituída por mulheres, sendo estas responsáveis pelos cuidados com a prole, porém já é perceptível na atualidade uma parcela de homens-pais desejosos de ter a guarda dos filhos.

Assim, com esta nova realidade da monoparentalidade masculina, evidencia-se a participação mais ativa do pai nos cuidados dos filhos e a demonstração de afeto e carinho. $\mathrm{O}$ homem mostra-se cada vez mais interessado em exercer esses cuidados e estar próximo da prole, mesmo após o fim da união conjugal. Isto é, esses pais não querem ser apenas visitantes, por isso, vão em busca de direitos iguais, de ter a guarda dos filhos e poder criá-los pessoalmente. A vivência paterna mais ativa potencializa uma nova forma de exercitar a paternidade, pois, os pais querendo conviver cotidianamente com seus filhos sentem-se, muitas vezes, encorajados em criar a prole sem a presença feminina no lar, formando, assim, uma família monoparental masculina.

Dessa forma, no presente estudo, o objetivo foi compreender como se caracteriza a monoparentalidade masculina, a partir da separação conjugal, na visão do pai. Além disso, procurou-se perceber o significado, na visão do homem, de ser pai no contexto da monoparentalidade; investigar quais as principais dificuldades encontradas pelo pai em 
exercer os cuidados com o filho; identificar os desafios da função paterna no contexto da monoparentalidade masculina.

\section{A família e a separação conjugal}

A família é um fenômeno social presente em todas as sociedades. As instituições que compõem uma sociedade se modificam ao longo do tempo. No caso da instituição familiar, não é diferente. Palma (2001) afirma que, antigamente, se admitia uma única espécie de grupo familiar, sendo formada pelo homem, a mulher e os filhos. No entanto, conforme a mesma autora, na concepção atual de família, essa definição não é mais tão clara.

Para compreender o significado de família, Hintz (2001) refere que é necessário buscar informações nas disciplinas de psicologia, biologia, antropologia social, sociologia e demografia. Todas estas áreas são unânimes em dizer que a instituição familiar vem passando por importantes modificações ao longo do tempo e que são decorrentes de mudanças no contexto sociocultural do indivíduo. Assim, diante das transformações da família na história, devemos considerar aspectos fundamentais como demografia, vida privada, papéis familiares, relações do estado com a família, lugar, parentesco, transmissão de bens, ciclo vital da família e rituais de passagem.

Nessa perspectiva, Wagner e Levandowski (2008) acrescentam que antigamente os laços de consanguinidade e parentesco eram parâmetros que definiam a configuração de uma família, porém, atualmente, há uma complexidade muito maior para que se consiga definir o que é uma família, pois se observa a existência de diversas configurações familiares, fazendo com que, consequentemente, o próprio conceito de família se diversifique, não importando mais apenas os laços de sangue e parentesco, mas também os laços afetivos. Desta forma, como não se tem um parâmetro para definir precisamente o conceito de família, sua composição e funcionamento, é importante se fazer uma análise aprofundada das famílias da atualidade, para melhor compreendê-las (WAGNER, TRONCO \& ARMANI, 2011).

Conforme Musito (2001) apud Wagner, Tronco e Armani (2011), pesquisadores do tema questionam a necessidade de se tratar a família de maneira pluralizada e não mais no singular, pois não é mais possível que um único conceito dê conta de tamanha complexidade. Além disso, essa pluralidade de variáveis para que se chegue a uma definição mais coerente com a realidade precisa abarcar as diversas configurações e estruturas familiares, ampliando cada vez mais as ideias sobre a família, como também suas implicações na sociedade, com a necessidade principal de aceitar e conviver com o diferente. Santana (2014) acredita que definir o conceito de família atualmente não é algo fácil, pois existem vários tipos de 
estruturas familiares e a concepção que cada uma delas tem de si precisa ser respeitada. Logo, não se pode afirmar que uma família é certa ou errada, pois cada família é única na sociedade.

Ao refletir sobre esse contexto, também é fundamental mencionar a realidade da separação conjugal, que é considerada um acontecimento cada vez mais presente no cotidiano das famílias brasileiras, devido ao número de divórcios que vem aumentando gradativamente ao longo dos anos, conforme apresentam os dados do Instituto Brasileiro de Geografia e Estatística (IBGE). O número de divórcios no Brasil cresceu 160\% na última década. Dados da pesquisa Estatísticas do Registro Civil 2014, divulgados pelo IBGE, mostram que, no ano de 2014 foram homologados 341,1 mil divórcios, um número bastante expressivo em relação a 2004, quando foram registrados 130,5 mil divórcios.

De acordo com Sousa (2010), quando o casal decide se separar, com frequência existem conflitos e questões emocionais não resolvidas por eles. Em alguns casos, o ex-casal já consumou a separação de fato, mas ainda não consolidou a separação emocional, conforme aponta Ribeiro (2000). Com isso, os ex-cônjuges vivenciam sentimentos de raiva, traição, vingança e desilusão com o casamento que se desfez. Vale lembrar que, muitas vezes, os filhos acabam envolvidos no conflito dos pais, como uma forma de atingir o (a) excompanheiro (a). Por isso, os filhos podem enfrentar medo e demais consequências negativas de um lar desfeito.

Com relação a isso, Schabbel (2005) destaca que pesquisas realizadas em outros países apontam, basicamente, para duas percepções que a separação conjugal provoca nos filhos: o medo, consciente ou inconsciente, de que o outro cônjuge também vá embora; e a percepção de que os adultos não são confiáveis e nem honestos. Além disso, é essencial mencionar que tanto o ex-casal quanto seus filhos passam por momentos delicados e difíceis na tentativa de resolver questões práticas da separação, como guarda e visita, além de questões emocionais, como lidar com a interrupção de certas tradições familiares, a perda da convivência diária com um dos pais e a sensação de desamor, rejeição e abandono.

Assim, entende-se que, em muitos casos, o processo de separação do casal implica em uma crise, podendo esta ocorrer em diferentes níveis e de formas mais ou menos adaptativas por todos os envolvidos, sendo que, após a separação o ex-casal necessitará arcar com as suas responsabilidades legais, sociais e emocionais a respeito dessa decisão (ROMARO \& OLIVEIRA, 2008). Além disso, tanto o homem quanto a mulher experimentam um profundo sentimento de dor no processo de ruptura do relacionamento conjugal e, embora o ex-casal vivencie a mesma dor, comportam-se diferentemente e manifestam de formas distintas seus 
sentimentos em relação à separação, o que pode estar mais relacionado a questões culturais, do que a distinções biológicas entre os sexos (FÉRES-CARNEIRO, 2003).

Desta forma, a separação conjugal legaliza um momento de desunião entre o casal, gerando, muitas vezes, um clima de disputa, capaz de criar novas estruturas de convivência entre pais e filhos e, principalmente, passível de provocar angústias e incertezas que ameaçam a estabilidade pessoal de todo o grupo familiar. Já para os filhos, a separação representa um mistério do qual não se tem conhecimento a respeito das causas, sendo necessário que estas sejam explicadas por ambos os pais com o máximo de transparência e objetividade (SCHABBEL, 2005). Para Boamorte (2014) a separação conjugal afeta todos os integrantes da família, por isso, é fundamental que o fim da relação conjugal seja discutido e explicado ao filho, pois o diálogo possibilita que os sentimentos sejam compartilhados e elaborados.

De acordo com Boamorte (2014) na maioria das vezes, o casal encontra dificuldades em colocar o filho em primeiro lugar após uma separação. Isto se deve a diversas razões, como o sofrimento do término da conjugalidade, as disputas judiciais, dentre outras. Em alguns casos nem sempre um casal se dissolve com o consentimento dos dois e quando um sai magoado da relação muito pior é para o filho, onde a parentalidade é prejudicada em detrimento do conflito conjugal. Quando o casal possui conflitos e não entra em um acordo, acaba recorrendo ao poder judiciário para resolver estes, com isso, os filhos se veem no meio de uma batalha judicial entre pai e mãe, onde a conjugalidade se confunde com a parentalidade.

A mesma autora afirma que a psicologia considera importante a presença dos pais para um bom desenvolvimento emocional do filho, no entanto estes pais precisam estar "inteiros" psicologicamente e o filho deve ocupar um lugar privilegiado em seu psiquismo. Para isso é fundamental que os pais sejam capazes de elaborar a separação e continuar a exercitar a parentalidade, pois sabemos que existe ex-casal, porém jamais ex-filho.

Neste sentido, é fundamental que o casal desenvolva claramente uma distinção entre a dissolução dos papéis de marido e mulher, para que após a separação haja uma reorganização dos papéis de pai e mãe, que não devem acabar após o fim da união conjugal. Grzybowski (2007) chama a atenção para a importância de se refletir a respeito da parentalidade após a separação conjugal, já que, apesar de existirem ex-cônjuges, não se pode defender que existam ex-mães e ex-pais. A conjugalidade e parentalidade não se dissociam totalmente após a separação, no entanto, não devem ser consideradas ou confundidas como um mesmo aspecto. Por isso, uma das grandes dificuldades na separação e um grande desafio a ser enfrentado por todos os envolvidos, é a diferenciação entre a conjugalidade, ser marido e ser 
mulher, e a parentalidade, ser pai e ser mãe (GRZYBOWSKI, 2011). Segundo Nazareth (2013) as responsabilidades dos pais, mesmo que separados, permanecem. O que se desfaz é o casal, ou seja, a conjugalidade rompe-se, entretanto a parentalidade persiste para sempre.

Frente a esse panorama, faz-se necessário diferenciar conceitualmente parentalidade de conjugalidade. Para Solis-Ponton (2004), a parentalidade é a capacidade psicológica de exercer a função parental, ou seja, ter a competência de ser pai ou mãe suficientemente bons para os filhos. Já, para definir conjugalidade é necessário fazer uma diferenciação com o conceito de vínculo conjugal. Conforme Sousa (2010), o termo vínculo conjugal designa aspectos de ordem relacional, afetiva ou psicológica, envolvidos no casamento, enquanto que, a conjugalidade é mais ampla, pois envolve aspectos psicológicos, sociológicos, históricos, jurídicos, bem como, a vida cotidiana. Com isso, embora a conjugalidade venha a ser desfeita com o fim do casamento, é possível que ainda perdure o vínculo conjugal entre os exparceiros. Fato este que talvez explique, pelo menos em parte, a dificuldade em separar conjugalidade de parentalidade diante do rompimento conjugal.

Outra consequência do rompimento conjugal que pode agravar ainda mais as questões relacionadas à conjugalidade e à parentalidade é o surgimento de dois núcleos (mono) parentais, e as diferentes adaptações iniciais que são necessárias e que se referem à definição de um novo padrão de equilíbrio e relacionamento nestas novas estruturas, ou seja, a redefinição de papéis, funções, responsabilidades e poder. Neste contexto, a adaptação inicial à separação depende, fundamentalmente, da elaboração do rompimento amoroso por parte dos pais (SOUZA \& RAMIRES, 2006).

Outro aspecto a ser refletido, dentro desse contexto da separação conjugal é com relação a guarda compartilhada dos filhos. Alves (2015) ressalta que a guarda dos filhos sempre foi regulamentada pelo Código Civil brasileiro. Este priorizava na maioria das vezes a mãe como responsável pela guarda dos filhos. Entretanto, como exposto no presente trabalho, a família passou por modificações e com isso a guarda passou a ser tratada visando o melhor para os filhos. Desta forma, a guarda antes defendida como unilateral teve sua regulamentação modificada, passando assim a ser defendida como compartilhada. A lei da guarda compartilhada $\mathrm{n}^{\mathrm{o}} 13.058 / 2014$ defende a convivência com genitores por período de tempo equilibrado, de maneira que ambos participem da criação contribuindo para o desenvolvimento dos filhos, além disso, a lei determina o envolvimento dos pais nas decisões sobre a vida dos filhos, exercendo assim efetivamente a maternidade e a paternidade, dando outros significados para a parentalidade e para a conjugalidade. 
Além disso, diante das mudanças ocorridas nos paradigmas familiares, a monoparentalidade é outra consequência proveniente da separação conjugal e é caracterizada por um dos genitores assumir sozinho as responsabilidades com a prole. No entendimento de Baliana (2013), a família monoparental refere-se a uma mãe ou a um pai a viver sem a presença do cônjuge e com filhos dependentes (crianças ou jovens adultos solteiros).

\section{A monoparentalidade:}

De acordo com Baliana (2013), a monoparentalidade não pode ser compreendida como um fenômeno moderno. Ela sempre existiu e tem evoluído consideravelmente nos últimos anos. Antigamente esse fenômeno ocorria de forma involuntária, pois era fruto de uma situação de viuvez. Atualmente, os motivos que levam a monoparentalide se estendem além da viuvez, como no caso da separação e do divórcio. A realidade da monoparentalidade tem ficado mais evidente nas últimas décadas, por isso, a importância de se refletir sobre esta temática, visando à compreensão deste modelo familiar cada vez mais presente na sociedade, sendo um fenômeno social que contempla todas as classes. Para Sousa (2008), a família monoparental vai de encontro ao modelo nuclear de família, indicando em sua estrutura a inexistência de um dos genitores: o pai ou a mãe, que assume sozinho os cuidados do filho. Portanto, a monoparentalidade pode ser definida quando apenas um dos pais vive com a prole na mesma casa.

Além disso, Sousa (2008) destaca que, o fenômeno da monoparentalidade sempre existiu, e nessa perspectiva, a família monoparental pode ser transitória ou definitiva. Configura-se como transitória quando acontece por determinado período na vida do genitor e seu(s) filho(s), sendo descaracterizada quando o genitor estabelece uma nova união estável. Por outro lado, a família monoparental pode se dar de forma definitiva, por exemplo, em consequência da separação conjugal sem nova união, da viuvez, da adoção ou por opção pessoal. Antigamente, a viuvez era uma das causas mais comuns para a formação da família monoparental, porém, atualmente, com o aumento das separações conjugais, esta se torna uma das causas mais comuns da monoparentalidade.

Santos e Santos (2009) afirmam que, na realidade da família monoparental, fruto de uma separação conjugal, o genitor guardião deve suprir as necessidades econômicas e também as afetivas, sendo que estas tarefas acabam por sobrecarregá-lo. Já os filhos, convivem diariamente sem a presença contínua do outro genitor (não guardião) e acabam por sofrer, muitas vezes, com a discriminação social fruto de preconceitos que dizem respeito a este modelo de família. 
Além disso, a família monoparental não enfrenta apenas o problema com a discriminação social, mas sofre também com a precariedade econômica, pois caberá ao não guardião o pagamento da pensão alimentícia para a prole, mas se ambos os pais trabalhavam, com a separação, a renda será dividida pela metade. No entanto, se apenas um dos pais trabalhava para suprir as necessidades da família e este deixa o lar, haverá a necessidade da família se reorganizar, ou seja, o genitor que ficar na responsabilidade de cuidar dos filhos, terá que trabalhar e haverá a busca pela pensão alimentícia (SANTOS \& SANTOS 2009).

Grande parte das famílias monoparentais é constituída por mulheres, sendo estas responsáveis pelos cuidados com a prole, porém já é perceptível na atualidade uma parcela de homens-pais desejosos de ter a guarda dos filhos. Diante disso, Santos e Santos (2009) chamam a atenção para a ideia arcaica que a sociedade ainda preserva a respeito de que a mãe, em comparação com o pai, possui mais capacidade para criar os filhos. Esta ideia é equivocada, pois alguns pais têm os mesmos potenciais da mãe para cuidar da prole e se observa o crescente número de pais que vão em busca da guarda unilateral do filho. Apesar disso, a maioria das guardas ainda é concedida às mães.

Diante desta nova realidade que envolve a paternidade, o censo de 2010 (IBGE) ainda aponta que as famílias monoparentais masculinas vêm ganhando destaque no cenário brasileiro pelo crescente número de pais que possuem a guarda da prole. No período de 1997 a 2007, a proporção de famílias monoparentais passou de $19,2 \%$ para $21,8 \%$, e no caso das famílias monoparentais masculinas, o percentual passou de $7,8 \%$ para $9,8 \%$, o que corresponde a 278 mil famílias monoparentais masculinas em 1997 e 445 mil em 2007.

Com relação especificamente à vivência da monoparentalidade, esta desencadeia diversas transformações na vida dos pais e dos filhos, o que não parece ser diferente comparando a monoparentalidade feminina com a masculina. Assim, a família monoparental produz variadas mudanças para seus membros, tais como estruturais, financeiras, psicológicas, relacionais, envolvendo perdas e ganhos, mas, além da responsabilidade nos cuidados e na realização dos demais encargos necessários (sobrecarga), há o benefício de a mãe ou o pai, estar na companhia dos filhos diariamente e de maneira mais próxima (SOUSA, 2008).

Como já mencionado, a posição de genitor pode ser ocupada tanto pela mãe, o que é mais predominante, quanto pelo pai. A seguir, será enfatizada a monoparentalidade masculina, objeto de estudo desta pesquisa. 


\section{A paternidade e a monoparentalidade masculina:}

As temáticas envolvendo a paternidade vêm ganhando destaque nas pesquisas, em função de vislumbrarem uma nova posição ocupada por homens que se constroem socialmente como novos pais. Goldenberg (2000) apresenta que, antigamente, a relação de pais e filhos era marcada pelo distanciamento e pela postura autoritária do pai. Nos dias de hoje, há mais proximidade quanto ao contato, participação mais ativa nos cuidados dos filhos e demonstração mais evidente de afeto e de carinho. Silva (2005) destaca, ainda, que o homem está cada vez mais interessado em exercer os cuidados e estar próximo da prole, mesmo após o fim da união conjugal, caracterizando um pai que não quer mais ser apenas visitante, mas o que busca direitos iguais de ter a guarda dos filhos e poder criá-los.

Em um estudo sobre a paternidade, Costa (2002) entrevistou homens com o objetivo de investigar suas representações sobre a paternidade e obteve como resultados que os homens-pais buscam viver a paternidade quebrando estereótipos do passado, assumindo uma postura mais ativa na relação com os filhos. Com isso, há uma ressignificação da figura paterna para o chamado "novo pai". Wagner (2011) salienta que o exercício do papel de pai na contemporaneidade, mesmo em contextos diferentes, é de participar do desenvolvimento da prole, não se restringindo apenas em provê-los e discipliná-los.

Diante de uma separação conjugal, ainda não são comuns os casos de guarda conjunta ou delegada ao pai, sendo isso fruto da organização tradicional de papéis de gênero que condicionou a estrutura familiar por muito tempo. Por essa razão, a decisão de que a guarda dos filhos deve ficar com a mãe, ainda é uma realidade comum nos tribunais (RAMIRES, 1997). Com isso, surgem as dificuldades do pai em exercer suas funções paternas, havendo um distanciamento da figura masculina na influência direta sobre os filhos, segundo Brito (2005).

No entendimento de Silva (2005), quando ocorre a separação conjugal e o pai não possui a guarda do filho, há a necessidade deste ir em busca de um espaço próprio junto ao filho. Prover apenas materialmente a prole não preenche as necessidades internas do homempai, pois este, muitas vezes, quer colaborar na criação e no sustento do filho em todos os seus aspectos. Por isso, o papel do pai nos dias de hoje é mais ativo na relação com a prole, mas como cada homem vai articular-se mediante essa exigência interna e externa de ser um pai ativo varia de homem para homem e, diante de qualquer rumo tomado, o que se espera é um pai próximo e mais disponível para o relacionamento com o filho.

Esta vivência paterna mais ativa potencializa uma nova forma de exercitar a paternidade, pois os pais querendo conviver cotidianamente com seus filhos sentem-se, muitas 
vezes, encorajados em criar a prole sem a presença feminina no lar, formando uma família monoparental masculina. Isso faz com que, nas últimas décadas, venha crescendo o interesse de homens em conviver com seus filhos diariamente e esses passam a lutar na justiça por essa possibilidade, visando a se dedicar totalmente às responsabilidades advindas da paternidade monoparental (SOUSA, 2008).

A guarda paterna é, também, prevista pela legislação brasileira, pois, o Novo Código Civil (BRASIL, 2002) evidencia que a guarda filial cabe ao genitor, seja ele o pai ou a mãe, que tiver melhores condições, não apenas financeira, para exercê-la. Assim, a tradição brasileira vem mudando ao longo do tempo, pois antes era comum a mãe assumir os cuidados com o filho, porém, atualmente, a clássica guarda materna, tendo o pai como visitante, já não é regra predominante nas famílias brasileiras (SOUSA, 2008).

A partir destas considerações, a figura masculina, diante do fato de ser pai, ultrapassa a visão mais tradicional para se dedicar a novos potenciais da paternidade, com capacidades básicas e necessárias para assumir as responsabilidades nos cuidados com os filhos. Porém, o pai monoparental, na maioria das vezes, não encontra exemplos anteriores de pais que foram mais participativos e, com isso, acabam recorrendo a figuras femininas para auxiliá-los nesta tarefa (SOUSA, 2008).

Por isso, o autor supracitado afirma que muitos homens que se posicionam ativamente diante da paternidade sentem estar mais "maternando" do que "paternando", em função dos significados tradicionalmente atribuídos à maternidade e à paternidade na sociedade. E que, apesar de os pais exercerem de forma satisfatória as funções tradicionalmente entendidas como maternas, não podemos desconsiderar a importância que a figura materna tem para os filhos. Portanto, cabe ao pai, ocupando efetivamente este lugar, estar próximo, dar carinho, atenção, educar, orientar e criar a prole, principalmente quando se vê na condição monoparental.

Diante da realidade até aqui apresentada, evidencia-se que o grande desafio de ser pai atualmente, numa realidade monoparental é encontrar o jeito próprio de exercer a paternidade, pois, como referido anteriormente, a maioria dos pais não possui um modelo anterior a ser seguido. Além disso, a sociedade ao longo das últimas décadas vem exigindo uma participação mais ativa e presente do pai na relação com os filhos. E, possivelmente, através da monoparentalidade masculina o homem tem a possibilidade de reconstruir esse papel de ser pai nos dias atuais, assumindo uma maior disponibilidade no relacionamento com o filho. 


\section{Método:}

A fim de responder os objetivos da pesquisa, foi realizado um estudo qualitativo, pois este lida com interpretações da realidade social, possibilitando maior profundidade sobre o fenômeno estudado (BAUER, GASKELL \& ALLUM, 2002). A escolha dos participantes foi realizada por conveniência, ou seja, amostra por acessibilidade. Participaram desta pesquisa, três pais, que moram na mesma residência de seus filhos. O projeto obteve aprovação do Comitê de Ética do Centro Universitário Franciscano sob o Parecer nº 330.267.

Os três participantes da pesquisa serão identificados a seguir, sendo mantido o sigilo quanto às identidades: Pai A, com 46 anos, é engenheiro da computação e foi casado por três anos. Possui há dois anos e meio a guarda da filha, que na época da entrevista estava com cinco anos e no momento da separação tinha três anos. O participante Pai A não possui relacionamento estável. O segundo entrevistado é o Pai B, com 48 anos, é empresário e foi casado dois anos e seis meses. Tem uma filha de 15 anos e possui a sua guarda há 11 anos. No momento da separação, a filha tinha 2 anos e com 4 anos de idade, o pai conseguiu a sua guarda. Este participante também não possui relacionamento estável. O terceiro entrevistado é o Pai C, com 52 anos, é advogado e bancário, tem dois filhos: um jovem de 20 anos e uma menina de 16 anos. Ficou casado sete anos e está separado há 13 anos. Está com a guarda dos filhos há sete anos e também não possui relacionamento estável. Em todos os casos as mães residem em outras cidades e não tem um contato frequente com os filhos.

O primeiro contato com os participantes foi realizado por telefone a fim de explicar os objetivos da pesquisa e garantir os direitos de sigilo e opção em participar do estudo. Posteriormente, foi marcado um dia para a realização das entrevistas semiestruturadas, sendo estas realizadas em dias e horários diferentes, de acordo com a disponibilidade de cada participante, quando, na ocasião, lhes foi disponibilizado o Termo de Consentimento Livre e Esclarecido.

Todas as entrevistas foram gravadas, sem tempo estimado, para melhor fidedignidade das informações e fluência da comunicação. Após a transcrição do material gravado, deu-se início a análise de conteúdo que, conforme Bardin (1977), avalia as comunicações visando a obter, por procedimentos sistemáticos e objetivos de descrição do conteúdo das mensagens indicadores (quantitativos ou não) que permitam a inferência de conhecimentos relativos às condições de produção/recepção (variáveis inferidas) destas mensagens. Assim, a partir da leitura das entrevistas foram identificadas as principais falas que diziam respeito aos objetivos da pesquisa, e as mesmas foram separadas em categorias para melhor discussão. 


\section{Discussão dos resultados:}

No decorrer da realização da pesquisa, os pais entrevistados demonstraram interesse pelo assunto, verbalizando vasto conteúdo para discussão científica. A partir da realização das entrevistas com os pais, foram definidas três categorias de análise: A constituição da monoparentalidade masculina a partir da separação conjugal; Os desafios do pai no contexto da monoparentalidade masculina e, por fim; $O$ significado de ser pai, que serão apresentadas e analisadas a seguir.

\section{A constituição da monoparentalidade masculina a partir da separação conjugal:}

Nesta categoria, serão discutidos os fatores que constituíram a monoparentalidade masculina a partir da separação conjugal, com base nas três entrevistas realizadas. O pai A, relatou que o relacionamento do casal começou a apresentar alguns sinais de que não estava bem e que, em função dessa tomada de consciência, ambos resolveram que a melhor opção seria a separação. No momento em que o casal decidiu por isso, os dois aceitaram a situação e decidiram que o homem ficaria responsável pelos cuidados da filha, pois este possuía melhores condições tanto financeiras quanto emocionais. Assim, concluí-se que a monoparentalidade se constituiu a partir da separação, pois a criança já ficou sob os cuidados do pai desde então.

O Pai A fala brevemente sobre a separação e explica o que levou o casal a optar por ele ficar com a guarda da filha:

\footnotetext{
O nosso relacionamento começou (...) a apresentar sintomas de que a coisa não andava bem. Naquele instante, eu, como pai, era a pessoa mais apta a lidar com a situação, não somente de maneira (...) econômica, social, financeira, mas também, eu teria mais tempo disponível, estaria mais psicologicamente estabilizado para lidar com aquela situação (PAI A).
}

Vieira e Souza (2010) afirmam que, nos casos em que a guarda for paterna, um dos principais motivos são as melhores condições materiais e financeiras do pai, para exercer o cuidado dos filhos. Além disso, o Pai A também mencionou que, mesmo antes da separação, participava das atividades referentes aos cuidados da filha, o que, de certa forma, contribuiu para que ficasse com a guarda dela. Essa realidade corrobora com as ideias de Vieira e Souza (2010) que referem que durante o casamento alguns homens podem ser mais participativos nos cuidados dos filhos do que as suas esposas, sendo que esta situação pode se manter após a separação conjugal.

Já para o Pai B, a constituição da monoparentalidade se deu de forma um pouco diferente, pois, no momento em que o casal se separou, a guarda da filha ficou com a mãe e o 
pai saiu de casa. Dois anos depois de separado, o Pai B solicitou a guarda da criança, pois, conforme relato, nos finais de semana, quando ficava com a filha, ele começou a perceber algumas questões relacionadas à saúde da menina, conforme exemplifica a passagem:

É que eu notei alguns maus tratos em relação a ela, não no sentido de baterem de judiarem dela, mas no sentido de que ela vinha sempre com rinites (...) aí eu comecei a ficar com o pé atrás (...). Notei que a mãe dela deixava ela muito com a babá, até fora de horário (...) daí foi um dos motivos que me fez pedir a guarda (PAI B).

Quando há a separação, o casal decide, muitas vezes, pela guarda materna justamente por acreditar que um filho pequeno deva ficar sob os cuidados da mãe, fato que aconteceu inicialmente no caso do Pai B. Porém, quando existem queixas referentes aos cuidados maternos, como mães que não se preocupam com os filhos, não se esforçam para estar próximas e, às vezes, negligenciam as necessidades dos mesmos, colocando em risco a sua saúde, o pai, assim como o Pai B, por estar preocupado com a saúde e o bem-estar da filha, procura assumir a guarda para cuidar melhor da criança (VIEIRA \& SOUZA, 2010).

A partir desta realidade, reforça-se a ideia de que o modelo patriarcal, onde a figura do pai era apenas de provedor, vem, ao longo das décadas, passando por mudanças, no que diz respeito principalmente ao maior envolvimento e um contato mais afetivo entre pai e filho. Sendo assim, o novo modelo de pai pode ser considerado como possuindo as mesmas capacidades das mães em exercer os cuidados com os filhos (SOUZA \& BENETTI, 2009).

Já a partir do relato do Pai C, conclui-se que, no seu caso, a monoparentalidade se constituiu anos após a separação do casal, pois quando estes se separaram, os filhos ficaram morando com a mãe. Depois de um tempo, aproximadamente seis anos, este pai resolveu retornar para sua cidade natal e a realidade familiar mudou, conforme indica o relato a seguir:

\footnotetext{
Quando eu decidi vir, final de 2006 (...) o menino, que tinha 14 anos disse: "pai, eu vou contigo, posso?", "não tem problema nenhum (...)" e ela [ex-esposa] liberou (...). Aí, ele veio morar comigo. E a menina, mais dois anos ela veio também; a mãe liberou. Ela [filha] manifestou interesse (...). E, desde então, eles moram comigo (PAI C).
}

De acordo com Tomaszewski (1997), a separação conjugal modifica também a vida dos filhos, havendo, dessa forma, necessidade de reorganização. Primeiramente, os filhos acabam perdendo um pouco de contato e convívio com o pai e a mãe na mesma casa. Além disso, há também a possibilidade da perda do convívio com os irmãos, pois pode ocorrer de um filho ir morar com o pai e o outro com a mãe. Neste momento, se faz necessário uma reconfiguração do grupo familiar, sendo constituída a monoparentalidade masculina ou feminina. 
Assim, entende-se que a constituição da monoparentalidade masculina se deu de formas distintas para os pais entrevistados. Com relação ao Pai A, a filha ficou com ele logo após a separação; já no caso do Pai B, o casal optou que a filha ficasse com a mãe, sendo que dois anos mais tarde o pai solicitou a guarda; e, para o Pai C, quando, houve a separação, os filhos ficaram com a mãe e anos depois, desejaram morar com o pai, que, em função disso, solicitou a guarda.

Constata-se, a partir dos relatos dos três pais, que a constituição da monoparentalidade se deu de forma não tão complicada, pois todos foram com o consentimento da ex-esposa. No caso do Pai A, desde o início da separação já se constituiu a monoparentalidade masculina. Nos casos dos Pais B e C, antes de eles assumirem a guarda dos filhos, houve um momento de monoparentalidade feminina.

É importante ressaltar que no caso do Pai C houve o desejo e um pedido dos filhos em ficar com ele. Diante disso, reitera-se a percepção atual de que alguns pais desejam assumir os cuidados dos filhos após a separação do casal. Fialho (2004) aponta que, quando um pai tem o desejo de ficar com o filho e vice-versa, a adaptação quanto às mudanças torna-se muito mais fácil.

Assim, vem crescendo atualmente o número de homens que anseiam em ter a guarda dos filhos, fato este que anteriormente era privilégio das mães, exceto em casos de viuvez, quando o pai assumia os cuidados dos filhos. Desta forma, percebe-se que alguns pais estão mais comprometidos e começam a dividir igualmente com as mulheres os cuidados e afazeres com os filhos, mesmo diante de uma separação conjugal (FIALHO, 2004), sendo a monoparentalidade masculina um exemplo disto.

\section{Os desafios do pai no contexto da monoparentalidade masculina:}

Nesta categoria, serão discutidas as principais dificuldades e os desafios elencados pelos pais no contexto da monoparentalidade masculina. No decorrer da entrevista do Pai A, este refere que o tempo é o principal desafio, pois, às vezes, ele não consegue destinar o tempo que gostaria para ficar com a sua filha, conforme relato:

O tempo passa muito rápido (...) e você não destinou aquele tempo que você gostaria pra pessoa (...) que você ama (...) todos os dias lotados e aí você chega e deixa a criança na escola (...) e só buscar de noite (...). E qual foi o tempo que eu destinei pra pessoa que eu poderia brincar me divertir. Eu gostaria de ter sempre muito mais tempo (...) eu acho que o tempo seria o maior desafio (PAI A).

Conforme Vieira e Souza (2010), a questão do trabalho está atrelada às dificuldades que alguns pais têm em conciliar seu tempo livre e o exercício da paternidade. Além disso, 
Prado, Piovanotti e Vieira (2004) sugerem formas de atuação para um pai que vive em uma sociedade complexa, onde é necessário que o pai aproveite o seu tempo com os filhos, mesmo que este seja restrito, por exemplo, aos horários das refeições, para interagir e também conversar com eles. Outra alternativa importante seria aproveitar os momentos de lazer, através de brincadeiras, de contar histórias, visto que as crianças gostam, principalmente, quando alguém tão significativo brinca com elas.

O Pai A também cita que uma das dificuldades enfrentadas se refere ao fato de quando tem que levar sua filha a um banheiro público. Nas palavras do entrevistado:

Eu a levo, por exemplo, no banheiro masculino sem problemas, se ela pede, porque ela já sabe ir ao banheiro sozinha, mas já aconteceu situações em que eu tive que entrar no banheiro feminino (...) "olha, desculpa, estou com a minha filha". Coloco um escudo na frente e vou entrando (PAI A).

Brito, Cardoso e Oliveira (2010) afirmam que esse tipo de situação não é socialmente facilitada, quando o pai que está sozinho e fora de casa necessita levar sua filha pequena ao banheiro. Percebe-se, na fala do Pai A, que esta dificuldade é mais situacional e o próprio entrevistado afirma que, em algumas situações, a filha, com seis anos acaba indo ao banheiro sozinha. Assim, neste caso, entende-se que o Pai A, busca formas para enfrentar estas situações e falar sobre elas.

Para o segundo entrevistado, o Pai B, o principal desafio está em não perder o contato com a filha, pois esta é adolescente e nesta fase, segundo ele, os jovens costumam ficar mais perto dos amigos. Sobre essa questão o participante diz:

\footnotetext{
Eu acho que o desafio maior agora é tu não perder muito o contato com eles, porque eles começam a ir mais para os lados dos colegas, inclusive eu falo pra ela que tem um monte de amigos (...) mas igual a família não existe né, não tem, pra ela procurar ir vendo que essa coisa da raiz da gente. Não adianta; tem que preservar ao máximo (PAI B).
}

Desta forma, Pratta e Santos (2007) salientam que o processo da adolescência afeta todas as pessoas que convivem diretamente com o adolescente. A adolescência tem influência direta no funcionamento da família, portanto esta fase constitui-se como um processo difícil e doloroso para adolescentes e também para os pais. Wagner et al (2002) referem que, a adolescência é uma fase que pode gerar uma série de conflitos no âmbito familiar, sendo que estudos salientam que há um aumento nas brigas e disputas entre pais e filhos. Além disso, a literatura aponta que o aumento desses conflitos está relacionado à diminuição do contato dos filhos adolescentes com seus pais (STEINBERG E MORRIS apud PRATTA E SANTOS, 2007). 
Ainda, o Pai B refere dificuldades com relação à menstruação da filha, fato também mencionado pelo Pai C: "eu achei que quando ela começasse a ficar menstruada, ela iria começar a ficar envergonhada. Capaz, na primeira vez "pai, eu tenho que comprar absorvente" (...). Volta e meia tem que pegar e sair de noite porque ela esqueceu de comprar [absorvente] com antecedência (...)" (PAI B).

Porém, o pai $\mathrm{C}$ relata que precisou recorrer à ajuda de familiares mulheres nesse momento, conforme evidencia-se na passagem: "eu tenho um apoio das minhas irmãs, que moram aqui. Então, elas conversam com ela [filha], explicam, né? Porque é sempre ruim para um pai abordar esses assuntos [menstruação] até porque o homem não sabe, mas, aí, as tias conversaram com ela" (PAI C).

Oliveira e Smeha (2012) indicam que o pai que não possui o apoio e a presença das mães de seus filhos sente a necessidade de, em alguns casos, contar com uma ajuda, ou seja, uma rede de apoio que dê suporte para essa adaptação, como corrobora a fala acima do Pai C.

De acordo com o pai $\mathrm{B}$, as dificuldades são em relação à comunicação dele com a filha, conforme observa-se na passagem:

\begin{abstract}
Às vezes, tem coisa que eu sei que ela só fala para a melhor amiga dela e isso aí é uma dificuldade normal, mas até a mãe tem, uma família, um pai tem, essa dificuldade da gente querer saber tudo (...). A L. [referindo-se a filha] não é muito de estudar e tem que ficar sempre dando uma puxada (...) mas se eu não cobrar que estude daqui a pouquinho eu não vou ter mais nada para cobrar (PAI B).
\end{abstract}

Wagner (2005) chama a atenção para o fato de que os pais, muitas vezes, dão importância aos estudos, pois é um valor que a cada dia que passa cresce na sociedade contemporânea, sendo que a cobrança que o Pai B refere, é esperada, devido às expectativas que se relacionam aos diferentes períodos escolares. Além disso, esse mesmo pai cita como exemplo de dificuldade o seu diálogo com a filha adolescente. Meneguetti e Gomes (2004) afirmam que, o diálogo para os adolescentes não é uma questão simples de ser estabelecida, pois um dos fatores que dificultam é o medo que os adolescentes têm das reações paternas ao que é falado.

De acordo com o pai $\mathrm{C}$, a principal dificuldade foi a fase da adolescência, conforme o relato: "acho que os piores momentos já passaram. Os problemas começam na préadolescência, que é uma idade difícil. Mas os dois [filhos] já venceram, estão livres; passaram incógnitos pelas drogas, por essa questão de más companhias” (PAI C).

A fase da adolescência é considerada um momento crítico e requer que o próprio adolescente se cuide, englobando também os cuidados dos pais e profissionais da saúde como psicólogos e assistentes sociais. Nesta fase, o jovem desenvolve atitudes desafiadoras com 
relação ao desconhecido e isto pode se tornar perigoso na medida em que o adolescente não possui diálogo com seus familiares (GONÇALVES, 2001). Essas ideias corroboram com as dificuldades apresentadas pelo Pai $\mathrm{C}$, o qual confessa as preocupações de um genitor que se diz responsável pelos filhos adolescentes.

Além disso, entende-se que as preocupações e dificuldades que os pais destacam com relação aos filhos não parecem ser muito diferentes caso o pai e a mãe estivessem morando juntos. O que pode dificultar um pouco mais, no caso da monoparentalidade, é que um dos pais está sozinho como responsável pelos cuidados dos filhos, tornando maiores as suas responsabilidades, além disso não tendo com quem dividir angústias e dúvidas. Porém, conforme os pais entrevistados nada impede que um pai sozinho possa morar com os filhos, principalmente se este aprende a conviver com eles sem a presença da mãe, enfrentando as dificuldades que surgem no dia a dia.

Diante do que foi exposto até o presente momento, evidencia-se que, se antes um homem exercesse a monoparentalidade, muitas vezes por não se sentir capaz ou até mesmo obrigado para tal tarefa, acabava recorrendo a uma figura feminina com o intuito de repassar a ela a responsabilidade sobre os filhos (SOUSA, 2008), porém, atualmente, percebe-se, que eles aceitam e assumem os encargos da monoparentalidade, não buscando a ajuda mais direta da mulher.

$\mathrm{Na}$ entrevista com o pai $\mathrm{C}$, este cita dois desafios principais que são as questões relacionadas com os afazeres de casa, da educação dos filhos e, a relação com a filha adolescente, mencionando:

(...) ao mesmo tempo que tu tem que cuidar de uma casa sozinho, tu tem os filhos, tu tem todas as tarefas, atividades inerentes à um lar, tu tem que manter um trabalho condigno (...). O maior desafio que eu vejo é com relação à menina, (...) tive que passar por todas essas situações da menstruação, [conversar sobre] a primeira transa (...). Tive conversas pra que ela me conte $[s i c]$, pra que a gente possa $[s i c]$ prevenir, mas eu não sei se ela vai me contar (PAI C).

Pratta e Santos (2007) destacam algumas preocupações parentais referentes aos adolescentes que são a iniciação sexual precoce e a ameaça do contato com as drogas. As influências do âmbito no qual o adolescente está inserido, tanto na família quanto no ambiente macrossocial, associadas às características de imaturidade emocional, impulsividade e comportamento desafiador que estão frequentes na maioria dos adolescentes, resultam em comportamentos de riscos, como por exemplo, a iniciação sexual precoce, a ausência de proteção durante o ato sexual e o uso de substâncias psicoativas (REBOLLEDO, MEDINA \& PILLON, 2004). 
Além disso, estudos apontam que os adolescentes se sentem mais próximos das mães quando querem conversar sobre determinados assuntos envolvendo, por exemplo, suas vivências íntimas, além de falarem sobre diversos assuntos, mais com a mãe do que com o pai (WAGNER et al, 2002). Desta forma, ainda se evidencia uma influência de gênero em relação aos papéis atribuídos aos pais na educação dos filhos, sendo a mãe, na maioria das vezes, ainda considerada a mais capacitada a exercer os cuidados com a prole, pois é ela seria quem aconselha e acompanha emocionalmente as crianças, e o pai teria o papel de prover, de sustentar financeiramente a família (WAGNER et al, 2005). Porém, na fala dos pais entrevistados fica claro que, na realidade, eles procuram ocupar este lugar e assumir este papel de cuidado e acompanhamento no desenvolvimento dos filhos.

Assim, fica evidente, através da fala dos pais participantes, que os desafios e as dificuldades apresentadas por eles no contexto da monoparentalidade masculina diferem das preocupações de uma família nuclear, no sentido de que o pai precisa lidar com essas situações sozinho, porém entende-se que algumas dificuldades que os pais expuseram no decorrer das entrevistas são típicas em função da fase que os filhos se encontram e da realidade que ambos vivenciam. Ou seja, grande parte das famílias, independentemente da sua configuração, também pode enfrentar as mesmas dificuldades relacionadas aos cuidados de um filho.

\section{O significado de ser pai:}

Nesta categoria, será discutido o significado de ser pai no contexto da monoparentalidade. No decorrer das entrevistas, cada pai contribuiu falando a respeito da sua experiência com a paternidade, conforme propõe o Pai B: "neste caso, além de pai, eu estou como mãe, tento exercer as duas funções. Ser pai é padecer no paraíso" (PAI B). Os entrevistados Pai A e C também colaboram afirmando "[a paternidade] é dar um caminho. E quando eu te falo "dar um caminho", o caminho é teu, então tu faz, pinta ele, enfeita ele do jeito que você quiser. Ser pai é dar um caminho o resto é a pessoa que recebe, que tem essa responsabilidade (PAI A). O Pai C afirma: [ser pai] é saber abrir mão de certas coisas. Ser pai é ter a capacidade de doação, é dar sem receber. Um filho é um investimento que tu faz sem ter a intenção de receber em troca. Na verdade, o retorno desse investimento é em amor (PAI C).

Pelo o que foi apresentado das entrevistas, percebe-se que ser pai não é uma tarefa fácil, pois exige muitas responsabilidades e o enfrentamento de grandes desafios no caso da 
monoparentalidade. Ser pai, na atualidade, mesmo em contextos diferentes, é ser participativo no desenvolvimento dos filhos e não apenas provê-los e discipliná-los. Compreende-se, assim, a existência de muitos pais conscientes e desejosos em exercer a paternidade, os quais buscam conquistar seus lugares nas relações com os filhos, sendo mais participativos no desenvolvimento e na formação da prole (STAUDT \& WAGNER, 2011).

A fala do Pai C traz sentimentos de afeto em relação à paternidade. Vieira e Souza (2010) apontam os aspectos afetivos na representação da paternidade, pois ela traz consigo, sentimentos de amor, carinho e satisfação, considerando os filhos centrais em suas vidas.

Além disso, chama a atenção a fala do Pai B, que relata exercer as duas funções, de pai e de mãe, o que coaduna com as ideias de Wagner (2002) no que se refere à realidade de pais que exercem tarefas educativas e diversas responsabilidades nos cuidados diretos com os filhos. Além disso, é importante ressaltar que, com as novas configurações familiares, está havendo uma desintegração da família tradicional e uma reorganização dos papéis sociais referentes ao homem e à mulher e, consequentemente, modificações no exercício da parentalidade e da própria paternidade, que não mais condizem com os papéis rígidos, desempenhados por cada gênero, o que fica evidente na fala dos pais com relação à monoparentalidade.

$\mathrm{Na}$ entrevista do pai C, este confessa que teve que abrir mão das viagens constantes do seu trabalho, pois percebeu que estava se ausentando frequentemente dos filhos. Conforme percebe-se na passagem “(...) no meu trabalho, eu viajava muito dando curso, e eu tive que abrir mão disso, era [sic] semanas longe de casa e aí coisas poderiam acontecer, então eu optei em ficar mais com eles [filhos]" (PAI C).

Esta fala harmoniza-se com as colocações de Fialho (2004), o qual afirma que existem casos em que os pais têm que abrir mão de certas atividades relacionadas ao trabalho, para ficarem mais próximos dos filhos e, assim, acompanhá-los no dia a dia, se esforçando para fazer o melhor por seus filhos. Somando-se a isso, conforme o referido autor, pesquisas apontam o aumento de pais que moram sozinhos com seus filhos destacando que a monoparentalidade masculina é possível e viável, assim como percebido nas histórias dos três pais entrevistados.

Outro aspecto mencionado pelos pais, que se refere ao significado de ser pai no contexto da monoparentalidade diz respeito às questões financeiras. O Pai C, esclarece: “em aspectos financeiros é caríssimo um filho (pai C)". O Pai B também contribui com a fala: tem as suas compensações, mas não aconselho ninguém a entrar nessa de ser pai ou mãe, que seja, 
sem pensar muito bem. Está muito complicado ter filho. É muito caro ser pai, mas tem o lado bom de ter alguém que reconhece o que tu está fazendo por ela [sic] (Pai B).

Assim, exercer a monoparentalidade decorre de um só genitor prover a casa, seja no plano econômico ou emocional, o que leva a afirmar que a monoparentalidade está ligada a questões tanto financeiras quanto emocionais (SANTOS \& SANTOS, 2009; SOUSA, 2008).

Além disso, é fundamental que os pais possam desempenhar um papel positivo, a partir da sua própria paternidade, pois é essa a referência que eles possuem, para exercer diariamente a paternidade. Com relação às dificuldades que os pais enfrentam para criar os filhos, o que predomina na família monoparental é o amor, pois o pai, muitas vezes, não cuida dos filhos porque é fácil, mas porque os ama. Nessa adição de amor, o pai tenta transmitir aos filhos segurança, para que estes encontrem a maneira mais eficaz de lidar com os sentimentos e as novidades que decorrem da família monoparental (SOUSA, 2008).

Desta forma, a percepção que os entrevistados têm sobre o significado de ser pai é marcada por grandes desafios, muitas responsabilidades, não sendo uma tarefa fácil. Para os pais em questão, o significado de ser pai é ser participativo no desenvolvimento e na formação dos filhos, além disso, isto efetiva-se na demonstração de sentimentos de afeto pelos filhos que representam para estes pais o exercício da paternidade monoparental.

\section{Considerações finais:}

A família, por ser um sistema que se move através dos tempos, vem passando por importantes transformações, surgindo com isso, novas formas de organização familiar. Esse estudo apresentou uma destas formas de organização: a monoparentalidade masculina, evidenciando que esta é uma realidade cada vez mais frequente na atualidade. Ou seja, o pai vivendo com os filhos e assumindo os cuidados e as responsabilidades com os mesmos. Diante disso, os pais entrevistados se mostraram completamente envolvidos com seus filhos, pois parecem exercer uma paternidade que vai além de cumprir obrigações básicas e passam a se envolver emocionalmente com os mesmos.

Embora o número de participantes deste estudo seja reduzido, o que limita uma generalização dos resultados, é importante reconhecer a relevância dos resultados obtidos. Eles apontam dados importantes e significativos de como vivem as famílias monoparentais masculinas atualmente, as suas principais dificuldades e também como se dão as relações afetivas com os filhos e o compromisso com o cuidado necessário para o bem estar destes. 
Assim, a fala dos pais entrevistados revela também e de forma significativa que os cuidados e as preocupações referentes aos filhos não diferem muito caso o pai e a mãe estivessem morando juntos. Nesse mesmo contexto, pode-se pensar que os cuidados paternos estariam no mesmo parâmetro daqueles realizados pela mãe, no que se refere, principalmente, ao afeto e à preocupação de estar presente de forma integral na vida dos filhos. Entende-se que nesses pais emerge um comportamento mais ativo e que eles assumem a responsabilidade total pelos filhos, ficando incumbidos de seu cuidado, pois parece ser influenciado pelo fato dos pais possuírem a guarda dos filhos por um tempo significativo.

Além disso, no decorrer das entrevistas, ficou evidente que a temática da monoparentalidade masculina traz momentos de angústia para esses pais, pois é um assunto, muitas vezes, delicado e complicado de se falar, pois envolve questões íntimas como, a separação conjugal, relação com a ex-esposa e os filhos. Apesar disso, foi possível observar que, esses pais tentam com empenho e dedicação encontrar o jeito próprio de exercer a paternidade, pois eles não possuem um modelo de geração anterior a ser seguido e buscam, através dos seus recursos pessoais dar conta desta tarefa, demonstrando que determinadas funções não precisam estar ligadas ao gênero, mas às potencialidades e ao desejo de ser pai neste contexto.

No que diz respeito às dificuldades e preocupações encontradas pelos pais no contexto da monoparentalidade masculina, constatou-se que pouco difere caso o pai e a mãe estivessem morando juntos, pois estas dificuldades que os pais expuseram em função do momento em que os filhos se encontram são esperadas e muitas mães e pais morando na mesma casa também podem enfrentá-las. Por essa razão, fica claro que alguns pais podem exercer sozinhos os cuidados com os filhos.

Quanto aos desafios, os pais acreditam que o principal é estarem próximos dos filhos, dando-lhes a atenção necessária e ficando mais tempo juntos. Isso faz com que ele necessite reorganizar sua rotina externa e pessoal para atender as necessidades dos filhos, cumprindo dois papéis, de ser pai e de ser mãe.

A percepção que os entrevistados têm sobre o significado de ser pai é que esta não é uma tarefa fácil, pois exige muitas responsabilidades, grandes desafios e principalmente ser participativo no desenvolvimento e na formação dos filhos. Neste contexto, entende-se que um aspecto facilitador seria os sentimentos de afeto na representação da paternidade destes pais, pois ela traz consigo sentimentos de amor, carinho e satisfação, considerando os filhos centrais em suas vidas. 
Fica evidente que essa paternidade monoparental não se faz sem conflitos e questionamentos, sendo marcada por avanços e retrocessos no dia a dia destes pais, pois percebeu-se que esta tarefa é assumida por eles com grande responsabilidade. Além disso, esta forma de exercer a paternidade parece ter provocado mudanças na vida destes homens e uma nova forma de se definirem enquanto pais a partir da escolha que fizeram: criar os filhos sem a presença da mãe.

Assim, o presente estudo respondeu os objetivos propostos, principalmente por lançar um olhar para estes homens neste momento tão peculiar de suas vidas, dando voz a eles. Porém, é necessária a continuidade nos estudos sobre esta temática, e além de ouvir os pais, dar voz aos filhos, pois este fenômeno ainda é pouco estudado.

Desta forma, a monoparentalidade masculina está em ascensão e vislumbra-se um novo lugar que os homens que são pais estão ocupando e construindo na sociedade. Concluise assim, que os pais estão assumindo uma postura mais ativa na relação com os filhos e, com isso, há uma ressignificação da figura paterna para um "novo pai", principalmente no contexto da família monoparental e suas especificidades.

\title{
AND WHEN IT IS NOT THE MOTHER? THE BEFORE MONOPARENTALITY FATHERHOOD
}

\begin{abstract}
:
This research aimed to understand how male monoparentality is characterized, considering marital separation, under the father's view. Currently, men seem to be increasingly interested in caring and being close to their children, even after the divorce, so they search equal rights to have children custody and to be able to create them personally. Data collection was made through semi-structured interviews with three fathers who live with their children. The results showed that the formation of male monoparental families occurred differently to each respondent. Considering difficulties faced by fathers in this context, they believe these problems are related to the stage where the children are and point out that many mothers and fathers living in the same home may also face the same difficulties related to children care. Therefore, nothing forbids a father from exercising children care by himself. About challenges, fathers believe that it is to be close to children, giving them the necessary attention and getting more time together. Furthermore, fathers percept being a father as a difficult task, because it requires a lot of responsibilities, there are big challenges, and especially because it is necessary to take part in the children's development and education. We conclude that nowadays fathers are taking an active stance in relation to children, trying to giving account of fatherhood in the context of monoparentality and, therefore, there is a reinterpretation of father figure to a "new father".
\end{abstract}

Keywords: Family; Male monoparentality; Fatherhood. 


\section{Y CUANDO NO ES LA MADRE? LA PATERNIDAD DIANTE DE MONOPARENTALIDAD.}

\section{Resumen:}

La investigación buscó comprender cómo se caracteriza la paternidad masculina, de la separación matrimonial, según la opinión del padre. En la actualidad, algunos hombres se manifiestan cada vez más interesados en el cuidado del ejercicio y estar cerca de los niños, incluso después del divorcio y van en pos de la igualdad de derechos para la custodia de los hijos y pueden crear ellos personalmente. La recolección de datos fue a través de entrevistas semi-estructuradas con tres padres, que viven con sus hijos. Los resultados mostraron que la formación de la familia progenitor masculino tomó de manera diferente a los encuestados. En cuanto a las dificultades encontradas por los padres, en este contexto, que ellos creen están relacionados con la etapa en que los niños son y hacen hincapié en que muchas madres y padres que viven en la misma casa también pueden enfrentarse a las mismas dificultades relacionadas con el cuidado de un niño. Así que es posible que uno de los padres es el único cuidado de un niño. En cuanto a los desafíos, los padres creen que es estar cerca de los niños, dándoles la atención necesaria y cada vez más tiempo juntos. Además, la percepción que los padres tienen sobre el significado de ser padre es que no es una tarea fácil ya que requiere muchas responsabilidades, los principales retos y sobre todo ser participativo en el desarrollo y la educación de los niños. Por lo tanto, se concluye que los padres están tomando una postura activa en relación con los niños, tratando de dar cuenta de la paternidad en el contexto de la familia monoparental y, por lo tanto, hay una redefinición de la figura paterna para un "nuevo padre".

Palabras Clave: Familia; Monoparentalidad masculina; La paternidad.

\section{Referências:}

ALVES, F. R. C. Guarda compartilhada: uma análise à luz do princípio do bem-estar e do interesse da criança e do adolescente. Trabalho de Conclusão de Curso (Graduação em Direito) - Universidade Federal do Rio Grande do Norte, 2015.

BALIANA, L. K. Monoparentalidade Feminina e seus Desafios: Um Estudo Exploratório. Dissertação de Mestrado em Politica Social. Lisboa: Instituto Superior de Ciências Sociais e Politicas, Universidade de Lisboa, 2013.

BARDIN, L. Análise de Conteúdo. Traduzido por Luiz Antero Reto e Augusto Pinheiro. Lisboa: Edições 70, 1977.

BAUER, M. W.; GASKELL, G.; ALLUM, N. C. Qualidade, quantidade e interesses do conhecimento - Evitando confusões. In: BAUER, M. W.; GASKELL, G. Pesquisa qualitativa com texto, imagem e som. Um manual prático. Petrópolis: Vozes, 2002. p. 1736.

BOAMORTE, J. B. O lugar do filho na separação conjugal. Psicologia.pt - O Portal dos Psicólogos. 2014. Disponível em: < http://www.psicologia.pt/artigos/textos/A0822.pdf> Acesso em 11 de Outubro de 2017.

BRASIL. Constituição (2014). Lei $\mathrm{n}^{\circ}$ 13.058, de 22 de dezembro de 2014. Altera os arts. $1.583,1.584,1.585$ e 1.634 da Lei no 10.406, de 10 de janeiro de 2002 (Código Civil), para 
estabelecer o significado da expressão "guarda compartilhada" e dispor sobre sua aplicação. Diario Oficial da União. 248. ed. Brasilia, DF, Disponível em: $<$ http://pesquisa.in.gov.br/imprensa/jsp/visualiza/index.jsp?jornal=1\&pagina $=2 \&$ data $=23 / 12 /$ 2014>. Acesso em: 11 out. 2017.

BRASIL. Lei $\mathrm{n}^{\mathrm{o}} 10.406$ de 10 de janeiro de 2002. Novo Código Civil. Diário Oficial da República Federal do Brasil, Brasília, DF, 01 jan. 2002. Disponível em: http://www.planalto.gov.br/Ccivil_03/LEIS/2002/L10406.htm. Acesso em: 02 mai. 2013.

BRITO, L. M. T. de; CARDOSO, A. R.; OLIVEIRA, J. D. G. de. Debates entre pais e mães divorciados: um trabalho com grupos. Psicologia Ciência e Profissão [online]. 2010, vol. 30, n. 4, pp.810-823.

BRITO, L. M. T. Guarda compartilhada um passaporte para a convivência familiar. In:_. Guarda compartilhada: aspectos psicológicos e jurídicos. Porto Alegre: Equilibrio, 2005. p. 53-71.

COSTA, R. G. Reprodução e gênero: paternidades, masculinidades e teorias da concepção. Revista de Estudos Feministas, Florianópolis, v. 10, n. 2, p. 339-356, 2002.

FIALHO, R. C. B. Enfoques sociais da família monoparental. Monografia de Pós Graduação. Universidade Candido Mendes, Rio de Janeiro, 2004.

FÉRES-CARNEIRO, T. Separação: o doloroso processo de dissolução da conjugalidade. Estudos de psicologia, vol. 8, n.3, p. 367-374, 2003.

GOLDENBERG, M. O macho em crise: um tema em debate dentro e fora da academia. In: GOLDENBERG, M. (Org.). Os novos desejos. Rio de Janeiro, Editora Record, 2000, p. 1339.

GONÇALVES, A. C. F. Conflitos de relacionamento entre pais e filhos adolescentes no contexto familiar. Dissertação de Mestrado. Universidade da Amazônia. Belém, Pará, 2001.

GRZYBOWSKI, L. S. Ser pai e ser mãe como compartilhar a tarefa educativa após o divórcio? In: WAGNER, A. e cols. Desafios psicossociais da família contemporânea. São Paulo: Artmed, 2011.

Parentalidade em tempo de mudanças: desvelando o envolvimento parental após o fim do casamento. Tese de Doutorado, Psicologia Social, Pontifícia Universidade Católica do Rio Grande do Sul, Porto Alegre, 2007.

HINTZ, H. C. Novos tempos, novas famílias? Da modernidade à pós-modernidade. Revista Pensando Famílias, Porto Alegre, n. 3, p. 8-19, 2001.

INSTITUTO BRASILEIRO DE GEOGRAFIA E ESTATÍSTICA. IBGE, 2014. Disponível em: www.ibge.gov.br/.

MENEGUETTI, A, D.; GOMES, W, B. Ser adolescente: um estudo sobre as percepções, dilemas, e reflexões adolescentes na família e na escola. Erechim, RS: EDIFAPES, 2004. 
NAZARETH, E. R. Família e Divórcio. In: CERVENY, Ceneide Maria de Oliveira (org). Família e...: comunicação, divórcio, mudança, resiliência, deficiência, lei, bioética, doença, religião e drogadição. São Paulo: Casa do Psicólogo, 2013.

PALMA, R. Famílias Monoparentais. Rio de Janeiro: Forense, 2001.

OLIVEIRA, L, C.; SMEHA, L, N. Quem disse que tem que ser a mãe? Os homens como cuidadores dos filhos. Anais do $5^{\circ}$ Interfaces no fazer psicológico - Direitos humanos, Diversidade e Diferença. mai/2012.

PRADO, A, B.; PIOVANOTTI, M, R, A.; VIEIRA, M, L. Não basta ser pai, tem que participar. Psicologia Brasil, v.2, n.12, p.12-16, 2004.

PRATTA, E. M. M.; SANTOS, M. A. Família e Adolescência: A Influência do Contexto Familiar no Desenvolvimento Psicológico de seus membros. Maringá: Psicologia em Estudo, v. 12, n. 2, mai/ago. p. 247-256, 2007,

RAMIRES, V. R. O exercício da paternidade hoje. Rio de Janeiro: Rosa dos Tempos, 1997.

REBOLLEDO, E. A. O., MEDINA, N. M. O., PILLON, S. C. Factores de riesgo asociados al uso de drogas em estudiantes adolescentes. Revista Latino-americana de Enfermagem, 12 (Número especial), p, 369-375, 2004.

RIBEIRO, M. L. A Psicologia Jurídica nos juízes que tratam do Direito de Família no Tribunal de Justiça do Distrito Federal. In: BRITO, L. M. T. (Org.). Temas de psicologia jurídica. Rio de Janeiro: Relume-Dumará, 2000, p. 161-170.

ROMARO, R.; OLIVEIRA, P. Identificação das queixas de adultos separados atendidos em uma clinica-escola de Psicologia. Psicologia Ciência e Profissão, n. 28, v. 4, 2008.

SANTANA, E. L. F. F. Família monoparental feminina: Fenômeno da contemporaneidade? POLEMMICA: Laboratório de Estudos Contemporâneos. Universidade do Estado do Rio de Janeiro, 2014, v. 13, n. 2, p. 1225-1236.

SANTOS, J. B. dos.; SANTOS M. S. da C. Família monoparental brasileira. Revista Jurídica, Brasília, v. 10, n. 92, out./2008 a jan./2009, p. 01-30. Disponível em: www.presidencia.gov.br/revistajuridica. Acesso em: 18 mai. 2013.

SCHABBEL, C. Relações familiares na separação conjugal: contribuições da mediação. Psicologia teoria e prática [online]. 2005, v. 7, n.1, p. 13-20.

SILVA, E. Z. M da. Paternidade ativa na separação conjugal. São Paulo: Editora Juarez de Oliveira, 2005.

SOLIS-PONTON, L. Ser pai, ser mãe: parentalidade: um desafio para o terceiro milênio. São Paulo: Casa do Psicólogo, 2004.

SOUSA, A. M. de. Síndrome da alienação parental: um novo tema nos juízos de família. In: O rompimento conjugal. São Paulo: Cortez, 2010. cap. 1 p. 21-48. 
SOUSA, A. P. de. Estudo comparativo das famílias monoparentais masculinas $\mathbf{X}$ monoparentais femininas: a influência do genitor no desenvolvimento familiar. Dissertação de Mestrado. Universidade Estadual Paulista Júlio de Mesquita Filho. Franca, São Paulo, 2008 .

SOUZA, C.; BENETTI, S. Paternidade contemporânea: levantamento da produção acadêmica no período de 2000 a 2007. Paidéia, v.19, nº42, Jun-Abr 2009. p. 97-106.

SOUZA, R. M. de.; RAMIRES, V. R. R. Amor, casamento, família, divórcio... e depois, segundo as crianças. São Paulo: Summus, 2006.

TOMASZEWSKI, A. de A. O dano moral no âmbito do direito de família - Filhos de pais separados. Dissertação de Mestrado. 1997. p. 189-214.

VIEIRA, E. N.; SOUZA, L. de. Guarda paterna e representações sociais de paternidade e maternidade. Aná. Psicológica [online]. 2010, vol. 28, n.4, p. 581-596.

WAGNER, Adriana (e colaboradores). Desafios psicossociais da família contemporânea. São Paulo: Artmed, 2011.

; LEVANDOWSKI, D. C. Sentir-se bem em família: um desafio frente à diversidade. Revista textos \& Contextos, Porto Alegre v. 7 n. 1, jan./jun. p. 88-97, 2008.

; CARPENEDO, C; MELO, L, P, de; SILVEIRA, P, G. Estratégias de comunicação familiar: a perspectiva dos filhos adolescentes. Psicol. Reflex. Crit. [online], vol. 18, n. 2, p. 277-282, 2005.

Como se perpetua a família? A transmissão dos modelos familiares. Porto Alegre: EDIPUCRS, 2005.

; FALCKE, D., SILVEIRA, L. M. B. O., MOSMANN, C. P. A comunicação em famílias com filhos adolescentes. Psicologia em Estudo. v. 7, n.1, jan/jun. p. 75-80, 2002.

Possibilidades e potencialidades da família: a construção de novos arranjos a partir do recasamento. In: WAGNER, A (org). Família em cena: tramas, dramas e transformações. Petrópolis: Vozes, 2002, p. 23-38.

Data de recebimento: $21 / 10 / 2014$.

Data de aceite: 08/12/2017.

\section{Sobre as autoras:}

Aline Tomazetti Denardi é Psicóloga, graduada pelo Centro Universitário Franciscano (UNIFRA). Endereço eletrônico: aline.denardi@yahoo.com.br 
Cristiane Bottoli é Psicóloga, Mestre em Psicologia e docente do Curso de Psicologia (UNIFRA) Endereço eletrônico: cbottoli@ hotmail.com 